\title{
Sustentabilidade organizacional: aplicação de índice composto em uma empresa do setor químico
}

\author{
Organizational sustainability: composite index application on a \\ chemical industry company
}

\author{
Cleber Augusto Scholl ${ }^{1}$ \\ Flavio Hourneaux Junior ${ }^{2}$ \\ Bárbara Galleli ${ }^{3}$
}

\begin{abstract}
Resumo: Este trabalho tem como objetivo propor a aplicação de um índice composto para mensuração da sustentabilidade organizacional em uma indústria química brasileira multinacional e avaliar sua importância como ferramenta de gestão. O estudo é baseado na metodologia desenvolvida por Krajnc \& Glavič (2005), que propõem um Índice Composto de Desenvolvimento Sustentável $-\mathrm{I}_{\mathrm{CDS}}$, gerado pela agregação de vários indicadores das dimensões econômica, ambiental e social, com o propósito de acompanhar o desempenho em termos de sustentabilidade de uma determinada empresa. Os indicadores relacionados aos temas considerados estratégicos para a empresa, após seleção, são normalizados, ponderados e agregados, constituindo três subíndices para, finalmente, serem associados e gerar um indicador global. O método foi aplicado na empresa Braskem, a maior empresa química brasileira, em que o índice composto foi calculado utilizando-se os indicadores reportados pela empresa por quatro anos, conforme diretrizes da Global Reporting Initiative (GRI), para relatórios de sustentabilidade. A ponderação dos indicadores foi subsidiada pelos macro-objetivos da visão da empresa, sendo que os indicadores considerados estratégicos receberam pesos comparativamente maiores. Os resultados da aplicação do modelo foram considerados satisfatórios, pois, além de fornecer números parciais de desempenho para cada dimensão avaliada, demonstrou-se que a ferramenta apresentou grande flexibilidade nas etapas de seleção, ponderação e normalização dos indicadores, possibilitando sua aplicação em diferentes contextos e empresas.
\end{abstract}

Palavras-chave: Indicadores de sustentabilidade; Modelo de avaliação de sustentabilidade; Indústria química; Global Reporting Initiative (GRI).

\begin{abstract}
This paper aims to propose the use of a composite index to measure organizational sustainability in a multinational Brazilian chemical industry and assess its importance as management tool. The study is based on the methodology developed by Krajnc \& Glavic (2005) that proposes a Composite Index of Sustainable Development - I generated by aggregating multiple indicators of economic, environmental and social dimensions, in order to monitor sustainability performance of a particular company. After selection, the indicators related to the company strategic are normalized, weighted and aggregated comprising three subindex to, finally, be associated and generate a global index. The method was applied to Braskem, Brazil's largest chemical company, in which the composite index was calculated using the indicators reported by the company for four years, according to the Global Reporting Initiative (GRI) guidelines for sustainability reporting. The indicators weighting was subsidized by the macro objectives of the company's vision, and the strategic indicators considered received comparatively higher weights. The model application results were considered satisfactory because, in addition to providing partial performance numbers for each dimension evaluated, the tool showed great flexibility in the stages of indicators selection, weighting and normalization, allowing its application in different contexts and businesses.
\end{abstract}

Keywords: Sustainability indicators; Sustainability assessment model; Chemical industry; Global Reporting Initiative (GRI).

\footnotetext{
${ }^{1}$ Apollus EHS Solutions (Administração), CEP 05001-100, Porto Alegre, RS, Brasil, e-mail: cleber.scholl@apollusehs.com.br

${ }^{2}$ Programa de Pós-Graduação em Administração, Mestrado Profissional em Administração - Gestão Ambiental e Sustentabilidade MPA-GeAS, Universidade Nove de Julho - UNINOVE, CEP 05054-010, São Paulo, SP, Brasil, e-mail: flaviohjr@uol.com.br

${ }^{3}$ Programa de Pós-graduação em Administração, Faculdade de Economia, Administração e Contabilidade, Universidade de São Paulo - FEA-USP, CEP 05508-900, São Paulo, SP, Brasil, e-mail: b.gallelidias@gmail.com
}

Recebido em Mar. 18, 2014 - Aceito em Jun. 8, 2015

Suporte financeiro: Nenhum. 


\section{Introdução}

A definição que se refere à sustentabilidade mais disseminada é aquela oriunda do denominado Relatório Brundtland, elaborado pela WCED, World Commission on Environment and Development, que relaciona a busca das satisfações das necessidades da geração atual, sem o comprometimento da capacidade das gerações futuras de satisfazerem as suas próprias necessidades (WCED, 1987). Apesar de muitas discussões conceituais, o que se tem notado é que enquanto as definições do termo são diversas (Lélé, 1991; Van Marrewijk \& Werre, 2003; Furtado, 2005; Vos, 2007; Doppelt, 2008), vários autores que firmam seus estudos sobre o tema convergem na abordagem reconhecida na literatura como triple bottom line - TBL (Elkington, 1999).

Como uma perspectiva de análise da sustentabilidade cada vez mais aceita pela sociedade e pelas organizações, assume-se que as atividades organizacionais se desenvolvem em um contexto que condiciona a qualidade e a disponibilidade de três elementos fundamentais para a gestão: o econômico, o ambiental e o social. Neste sentido, a sustentabilidade organizacional refere-se às atividades da empresa que demonstram a inclusão de aspectos sociais e ambientais às suas operações econômicas e interações com stakeholders (Van Marrewijk \& Werre, 2003), sem que a capacidade de sustentar as necessidades de gerações futuras seja comprometida (Dyllick \& Hockerts, 2002). Assim, a sustentabilidade deve representar um novo modo de agir da organização, e não apenas incidir sobre práticas voluntárias e respostas às exigências dos stakeholders (Valente, 2012).

Apesar da grande relevância do tema, o que se tem notado, é que tanto a compreensão deste fenômeno para o meio empresarial, como a ocorrência de sua operacionalização, ainda não se apresentam de forma significativa (Stubbs \& Cocklin, 2008), apesar de se perceber maior número de iniciativas relacionadas a orientações para divulgação das ações organizacionais ditas sustentáveis, além da distância entre a retórica e a realidade, quando o assunto é a implantação de práticas de gestão da sustentabilidade e a dissociação da gestão ambiental das demais atividades organizacionais (Hahn \& Scheermesser, 2006; Vos, 2007; Hacking \& Guthrie, 2008; Barkemeyer et al., 2014).

O fato é que práticas como certificações, indicadores e relatórios voltados à sustentabilidade nas organizações têm proliferado na última década. Observa-se grande interesse - pautado principalmente por pressões de stakeholders - na tentativa de medir e avaliar o progresso das empresas em relação à sustentabilidade. Ao realizar um levantamento, Van Bellen (2004) identificou dezoito metodologias ou instrumentos de avaliação da sustentabilidade mais relevância na literatura científica. Hák, Moldan \& Dahl (2007) destacam uma série de iniciativas internacionais - que podem ser modelos, conjunto de indicadores ou índices, relacionados à sustentabilidade, encontradas tanto no âmbito do TBL, quanto em âmbitos conceituais diversos.

Iniciativas importantes, como os indicadores relativos às Metas do Milênio, o conjunto de indicadores da Comissão de Desenvolvimento Sustentável - ambos das Nações Unidas -, o índice de Pegada Ecológica (Ecological Footprint), o Living Planet Índex, da WWF (World Wildlife Fund), entre outros, têm sido disseminadas mundialmente. Cada uma dessas iniciativas possui enfoques, objetivos e metodologias específicas e são geralmente utilizadas em nível macroeconômico.

Tratando-se do nível organizacional, Vinodh (2011) elencou vinte referências de trabalhos científicos, publicados entre os anos de 1997 e 2009, provenientes de diversas partes do mundo, sobre organizações nas quais são encontradas várias ferramentas de gestão e avaliação da SO, com destaque para construções e aplicações de indicadores e métricas sociais, ambientais e da sustentabilidade em si. Já Singh et al. (2009) também fazem um extenso levantamento das ferramentas que possam indicar, de forma agregada, a situação da sustentabilidade nas organizações. Os autores se propõem a compilar 41 diferentes abordagens que possam ajudar na formulação estratégica e na formação, normalização, atribuição de pesos e agregação de dados para possibilitar a avaliação da sustentabilidade organizacional.

Em função da importância do tema, diversos trabalhos têm buscado trazer luz à questão da mensuração integrada da sustentabilidade nas organizações também em diferentes setores. Assim, estudos retratam a indústria mineral (Azapagic, 2004); têxtil (Zamcopé et al., 2012); agrícola (Guttenstein et al., 2010); de óleo e gás (Infante et al., 2013); e de aço (Singh et al., 2007), por exemplo.

Diante de tais considerações, este trabalho tem por objetivo propor a aplicação da metodologia do índice desenvolvido por Krajnc \& Glavič (2005) em uma indústria química brasileira multinacional e avaliar sua importância como ferramenta de gestão da SO. Questões relacionadas à sustentabilidade neste setor são especialmente relevantes, em função de diversos fatores: trata-se de uma indústria de extrema relevância econômica, sendo o quarto maior setor industrial no caso do Brasil, com um faturamento total próximo dos R \$ 300 bilhões em 2013, respondendo por $2,5 \%$ do Produto Interno Bruto no país (ABIQUIM, 2013), e em termos mundiais, o valor é equivalente a $€ 2.744$ bilhões em 2011 (CEFIC, 2012). Além disso, constitui-se naturalmente em um setor de alta tecnologia e fortemente regulamentado, mas cujas práticas de sustentabilidade (principalmente na dimensão social) permitem espaço para seu desenvolvimento (Majumdar et al., 2009). O setor ainda carece de 
novos elementos para enfrentar uma realidade em que a sustentabilidade será, cada vez mais, um elemento crítico para essa atividade (Mulderink, 1998; Kleizen, 2006; García-Serna et al., 2007; Hall \& Howe, 2010).

\section{Sustentabilidade e sua mensuração nas organizações}

Epstein (2008) destaca que as constantes incertezas sobre o quanto a sustentabilidade é necessária, o quanto ela custa e também quanto ao horizonte de tempo necessário para medir seus benefícios, tornam difícil implementá-la da mesma forma que outras iniciativas estratégicas. Para integrar informações sobre os impactos do social e do ambiental em decisões do dia a dia da gestão, espera-se que as empresas encontrem meios de amarrar a medição e a comunicação desses impactos em processos de decisão.

Algumas organizações, ao reconhecerem os efeitos sociais e ambientais de suas ações econômicas, buscam meios capazes de declararem suas ações de sustentabilidade, usualmente por meio da publicação de relatórios de sustentabilidade. Barkemeyer et al. (2014) afirmam que uma das questões fundamentais para a operacionalização da SO é a expansão da prática dos relatórios baseados no TBL, em que há a divulgação de informações qualitativas e quantitativas, por meio de indicadores. De fato, nos últimos anos, esse padrão de publicação dos relatórios de sustentabilidade vem sendo crescentemente adotado por empresas nacionais e internacionais que buscam evidenciar com maior transparência informações socioambientais ao público interessado e aos seus stakeholders (Leite e Filho et al., 2009).

Partindo-se, portanto, da ideia do TBL, observa-se que, para além do que sua tradução literal pode parecer significar, tal abordagem levaria a organização a capturar a essência da sustentabilidade ao permitir mensurar os impactos das atividades de uma organização tanto na esfera econômica, quanto social e ambiental (Savitz $\&$ Weber, 2007). Tal impacto seria apreendido por meio de indicadores relativos às três dimensões e também serviria como uma referência ou " [...] uma metáfora que nos faz lembrar que o desempenho organizacional é multi-dimensional [...]" (Pava, 2007, p. 108).

Indicadores e índices de sustentabilidade são amplamente reconhecidos como instrumentos importantes para elaboração de políticas, para transmitir informações e como forma de mensuração do desempenho corporativo nas áreas ambientais, econômicas, sociais e tecnológicas (Singh et al., 2009), pois tem a capacidade de simplificar, quantificar, analisar e comunicar elementos, antes complexos e de difícil entendimento (Warhurst, 2002). No entanto, a compreensão do significado dos termos índice e indicador pode gerar alguma confusão, sendo que em alguns casos são usados, erroneamente, como sinônimos.
De forma geral, a maior diferença entre eles estaria relacionada ao nível de agregação da informação, maior para o índice e menor para o indicador (Hammond et al., 1995; Shields et al., 2002). Um índice é o valor agregado final de todo um procedimento de cálculo no qual se utilizam, inclusive, indicadores como variáveis que o compõem; é um dado mais apurado que provém da associação de um conjunto de indicadores ou variáveis e que pode interpretar mais fielmente a realidade de um sistema (Siche et al., 2007). Já um indicador seria “[...] um parâmetro ou um valor derivado de parâmetros, que provê informação sobre um fenômeno/ambiente/área ou descreve o seu estado, com um significado extensivo e é diretamente associado com um valor de referência [...]" (OECD, 2003).

De qualquer modo, dependendo da aplicação esperada, índices e indicadores podem não possuir um mesmo significado conceitual; no entanto, ambos medem a aproximação da realidade, e não a realidade precisa (Van Bellen, 2005). O que, de fato, será fundamental para a adoção de um índice de sustentabilidade é a metodologia escolhida para fazê-lo, que deve ser clara e transparente, não deixando dúvidas sobre quais os princípios que estão na base do processo (Siche et al. 2007).

Existe uma série de conjuntos de indicadores sistematizados em diretrizes criadas por instituições que visam oferecer um caminho para a sustentabilidade. Entre as práticas mais disseminadas no Brasil estão: Balanço Social IBASE (Instituto Brasileiro de Análises Sociais) (IBASE, 2012); Indicadores ETHOS de Responsabilidade Social Empresarial (Instituto Ethos, 2008); Conselho Empresarial Brasileiro para o Desenvolvimento Sustentável (CEBDS, 2007); e Global Reporting Initiative (GRI) (GRI, 2012). Além disso, há o chamado Relato Integrado, a cargo do International Integrated Reporting Council (IIRC), criado oficialmente em 2010 e disseminado na Conferência das Nações Unidas para o Desenvolvimento Sustentável, realizada no Brasil em junho de 2012, a RIO+20 (IIRC, 2013).

Dentre elas, têm ocupado crescente espaço nas discussões da sustentabilidade nas organizações as diretrizes GRI. A Global Reporting Initiative é uma rede com a participação de representantes de diversos setores da sociedade (empresas, organizações não governamentais, peritos, agências governamentais, entre outros), presentes em mais de 40 países, que participam em grupos de trabalho e órgãos de governança do GRI e determinam as diretrizes para a realização de relatórios de sustentabilidade de forma global. As diretrizes da GRI são consideradas um dos principais padrões no mundo para a construção dos relatórios de $\mathrm{SO}$, inclusive como referência para a elaboração de relatórios setoriais (Staniškis \& Arbačiauskas, 2009). 


\section{Metodologias de medição integrada de desempenho da sustentabilidade organizacional}

A utilização de sistemas formais para o acompanhamento da sustentabilidade nas organizações, por meio de ferramentas que permitam sua mensuração e avaliação, parece ser um consenso, enquanto necessidade e desafio. Tendo em vista sua principal função de suporte ao processo de tomada de decisão, acredita-se, assim como argumentam Kranjc \& Glavič (2005), ser necessária às organizações a adoção de medidas agregadas que indiquem a sustentabilidade nas organizações.

Ao buscar-se na literatura científica por modelos propostos para a mensuração de sustentabilidade organizacional que utilizaram indicadores ambientais, econômicos e sociais de maneira agregada, chegou-se aos trabalhos de Callado \& Fensterseifer (2011), Vinodh (2011) e Krajnc \& Glavič (2005).

Callado \& Fensterseifer (2011) propõem a mensuração da sustentabilidade empresarial a partir do Grid de Sustentabilidade Empresarial (GSE). A operacionalização do modelo proposto foi realizada inicialmente a partir da seleção de indicadores de sustentabilidade, elencados por meio da literatura científica e submetido à apreciação de dez especialistas. Ao final do julgamento dos especialistas, foi estabelecido um total de 43 indicadores de sustentabilidade, sendo 16 indicadores ambientais, 14 econômicos e 13 sociais. Na sequência, são definidos os Escores Parciais de Sustentabilidade (EPS), com um conjunto de indicadores de cada uma das três dimensões do TBL $\left(\mathrm{EPS}_{\mathrm{A}}=\right.$ ambiental $^{\mathrm{EPS}} \mathrm{E}_{\mathrm{E}}$ $=$ econômico e $\mathrm{EPS}_{\mathrm{S}}=$ social $_{\text {, }}$ com pesos específicos atribuídos por especialistas. Ao final é calculado um índice agregado de sustentabilidade, o Escore de Sustentabilidade Empresarial (ESE), dado por: ESE $=\mathrm{EPS}_{\mathrm{A}}+\mathrm{EPS}_{\mathrm{E}}+\mathrm{EPS}_{\mathrm{S}}$

Os autores ainda propõem o Grid de Sustentabilidade Empresarial (GSE), que permitiria avaliar e classificar diversas empresas e/ou grupos de empresas, independentemente do porte, setor de atividade e demais características por meio do ESE. Segundo os autores, o modelo pode ser utilizado como instrumento de avaliação de resultados associados às práticas de sustentabilidade empresarial, por empresários, gestores, empresas de auditorias, organizações governamentais e não governamentais, dentre outros possíveis usuários, desde que possuam conhecimentos associados à sustentabilidade empresarial e dimensões de sustentabilidade (Callado \& Fensterseifer, 2011).

Em outro estudo, Vinodh (2011) elabora um modelo de avaliação da sustentabilidade com base nas três dimensões do TBL: econômica, ambiental e social. No que tange à parte conceitual do modelo, o autor aponta três níveis subsequentes que o constituem: (a) capacitores da sustentabilidade, composto pelas três dimensões citadas; (b) critérios da sustentabilidade, com 12 itens distribuídos entre os três capacitores; e (c) atributos da sustentabilidade, no qual 37 são dispostos entre os 12 critérios.

A partir da elaboração deste modelo conceitual, Vinodh (2011) desenvolve então o modelo de avaliação da sustentabilidade por meio da lógica fuzzy. Para tanto, o primeiro aspecto a ser apresentado é uma equação que representa o índice de sustentabilidade organizacional, dado pela fórmula $I=W x R$, em que, $I$ representa o índice de sustentabilidade, $W$ representa o peso dado a cada um dos capacitores, critérios e atributos da sustentabilidade, e $R$ é o vetor, resultado do cálculo estatístico dos pesos. O modelo de avaliação é composto por cinco intervalos, conforme as premissas da lógica fuzzy: o intervalo de 8-10 corresponde à 'extremamente sustentável'; de 6-8 representa 'sustentável'; de 4-6 significa 'sustentável em geral'; de 2-4 representa 'não sustentável' e menos que 2 corresponde a 'extremamente não sustentável'.

Para a operacionalização do modelo de avaliação, houve a participação de cinco experts cuja função foi conferir notas aos atributos, critérios e capacitores da sustentabilidade, de acordo com sua importância, de 0 a 10. Por meio de cálculos estatísticos, destas notas foram angariados pesos a cada um dos atributos, critérios e capacitores da sustentabilidade, respectivamente (Vinodh, 2011).

Finalmente, o modelo construído por Krajnc \& Glavič (2005) propõe um Índice Composto de Desenvolvimento Sustentável $\left(\mathrm{I}_{\mathrm{CDS}}\right)$, a partir da agregação de uma série de indicadores das três dimensões do TBL, que se constituem em subíndices do Desenvolvimento Sustentável. Na validação de seu modelo, os autores realizaram um estudo empírico em uma indústria alemã, cujas informações do período de seis anos foram coletadas. Depois de selecionados 6 indicadores para a dimensão econômica, 22 para a ambiental e 10 para a social, os pesos foram atribuídos a partir da matriz de comparações pareadas e a normalização feita pelos valores mínimos e máximos. Depois de feitos os cálculos para todos os indicadores, os resultados foram agregados nos valores dos três subíndices e, finalmente, no índice de sustentabilidade. Dispostos em um gráfico, foi evidenciado o progresso da organização estudada, e foi constatado que esta se encontrava progredindo positivamente ao longo do tempo em seu desempenho da sustentabilidade (Krajnc \& Glavič, 2005). O I $_{\text {CDS }}$ será a base da metodologia utilizada neste trabalho e será apresentada em detalhes na sequência, no item 5.2.

\section{Aspectos metodológicos}

Para atingir os objetivos deste estudo, foi realizada a aplicação da metodologia de Krajnc \& Glavič (2005) em uma empresa que pudesse atender às 
características necessárias do estudo, principalmente ter uma orientação estratégica com a sustentabilidade e instaladas ferramentas e práticas que dão suporte à sustentabilidade na organização. Dessa forma, a partir de acordo com os critérios de um estudo de caso único (Yin, 2001), e por facilidade de acesso e interesse da própria empresa em realizar as análises propostas, a Braskem S.A. foi definida como objeto da pesquisa. Antes, porém, de apresentar a empresa estudada e a aplicação da pesquisa, cabe esclarecer a opção pela metodologia empregada, a proposta de Krajnc \& Glavič (2005).

Inicialmente, destaca-se sua estrutura, semelhante à estrutura das diretrizes GRI. Como os próprios autores mencionam, uma das maiores vantagens de ter como referência a metodologia da GRI está na possibilidade de se utilizar o benchmarking e comparações, visto que é um formato padrão reconhecido mundialmente (Krajnc \& Glavič, 2005). Também por esta razão, o guia desenvolvido pela GRI tem sido utilizado em um grande número de organizações, especialmente industriais, como é o caso da empresa analisada, que já faz uso das diretrizes GRI há vários anos.

De fato, apesar de as estruturas dos modelos elaborados por Callado \& Fensterseifer (2011) e Vinodh (2011) assemelharem-se a da GRI, com indicadores para cada uma das três dimensões da SO (econômica, social e ambiental), em nenhum desses estudos se encontra referência a tal fonte. Callado \& Fensterseifer (2011) basearam-se em trabalhos acadêmicos e em opinião de especialistas, enquanto Vinodh (2011) faz menção apenas ao TBL. Não é intenção repudiar ou desvalorizar o trabalho dos autores; pelo contrário. A ideia é destacar que a utilização de metodologias reconhecidas internacionalmente, como a da GRI, proporciona vantagens, possibilidades de aplicação e credibilidade com maior ênfase que outras.

Outro ponto que se destaca na proposição de Krajnc \& Glavič (2005) é o fato de a temporalidade ser incluída como fator básico no cálculo do índice de sustentabilidade, o que não é visualizado nos outros dois estudos. Ao ser considerado, o fator tempo contribui para o processo decisório, propiciando uma visão mais ampla aos gestores que uma visão estática do desempenho da organização neste aspecto. A sustentabilidade organizacional, em suas três dimensões, não é algo fixo, mas dinâmico. Assim, demanda análises da mesma natureza, ou que ao menos se aproximem desta necessidade.

Há que se ressaltar que os trabalhos de Callado \& Fensterseifer (2011) e de Vinodh (2011) fornecem uma classificação para o desempenho de sustentabilidade atingido, enquanto o de Krajnc \& Glavič (2005) não o faz. Este não deve ser um fator limitador, pois, segundo a proposta dos autores, a análise do resultado do $\mathrm{I}_{\mathrm{CDS}} \mathrm{e}$ feita com base no desempenho da própria organização ao longo do tempo. Tal circunstância permite que os objetivos estabelecidos sejam verificados, assim como a estratégia organizacional, uma vez que é a partir dela que as ponderações para os indicadores são obtidas.

Além disso, no trabalho de Krajnc \& Glavič (2005), assim como no de Vinodh (2011), é preciso ressaltar a indicação de que a ponderação dos indicadores seja feita por gestores conhecedores da realidade da organização, e não, previamente, por especialistas distintos. Novamente, não se retira o mérito dos especialistas; entretanto, a questão é que, ao serem ponderados por especialistas internos à empresa, eleva-se a tendência de acurácia dos indicadores em refletir a realidade - estratégia - almejada. Os tomadores de decisão de uma mesma organização possuem diferentes visões e estão interessados em diferentes indicadores. O mesmo ocorre para organizações diferentes que, acima disso, possuem estratégias diferenciadas. Logo, a ponderação feita por profissionais internos pode ser mais adequada.

Diante de tais considerações, percebe-se que a proposta de Krajnc \& Glavič (2005) apresenta mais pontos favoráveis que os outros dois analisados: a utilização de uma referência internacional como base; a inclusão da temporalidade; a consideração de especialistas internos para a ponderação de indicadores e da estratégia organizacional.

\section{Aplicação da metodologia de Krajnc \& Glavič (2005) no caso Braskem S.A.}

\subsection{A empresa Braskem S.A.}

A Braskem S.A. é hoje a maior produtora de resinas termoplásticas das Américas, sendo o maior produtor mundial de biopolímeros com o polietileno verde e também o maior produtor de polipropileno nos Estados Unidos. Suas unidades industriais estão localizadas no Brasil, Estados Unidos e Alemanha, países onde a empresa também mantém escritórios de negócios centros de tecnologia e inovação, além de escritórios comerciais e bases na Argentina, Chile, Colômbia, Holanda e Singapura (BRASKEM, 2013). A empresa tem 445 patentes depositadas no Brasil, Estados Unidos e Europa, e seu lucro líquido foi de $\mathrm{R} \$ 33,2$ bilhões em 2011 (cerca de US\$ 17 bilhões) (BRASKEM, 2011).

Criada em 2010, a chamada "Visão 2020" define o crescimento em longo prazo da empresa como "ser a líder mundial da química sustentável, inovando para melhor servir às pessoas". A Visão 2020 contempla três pilares estratégicos para a sustentabilidade: fontes e operações cada vez mais sustentáveis; portfólio de produtos cada vez mais sustentável; e soluções para que a sociedade tenha uma vida mais sustentável (BRASKEM, 2012). Seu posicionamento é reforçado 
por seus sete macro-objetivos, criados de acordo com as diretrizes da Conferência Rio+20: (i) gases de efeito estufa; (ii) eficiência energética; (iii) eficiência hídrica; (iv) segurança química; (v) matéria-prima renovável; (vi) pós-consumo; e (vii) pessoas (BRASKEM, 2011). A empresa também segue as estratégias e políticas definidas pela sua holding (Organização Odebrecht), e os valores e princípios de governança praticados são: integridade, transparência, igualdade, responsabilidade, continuidade e ética (BRASKEM, 2013).

A Braskem é a maior produtora de resinas termoplásticas das Américas, em especial de Polietileno (PE) e Polipropileno (PP). Em 2004, a empresa elaborou o $1^{\circ}$ Relatório de Desenvolvimento Sustentável. Já em 2005, foi listada no Índice de Sustentabilidade Empresarial (ISE) da BM\&F Bovespa, no qual continua até hoje. No ano de 2007, a empresa foi a primeira a lançar o polímero verde - polietileno de alta densidade produzido a partir da cana-de-açúcar (BRASKEM, 2011).

\subsection{Definição da metodologia de cálculo}

O modelo construído por Krajnc \& Glavič (2005) propõe a agregação de uma série de indicadores, reduzindo-os em um índice composto, denominado Índice Composto de Desenvolvimento Sustentável $\left(\mathrm{I}_{\mathrm{CDS}}\right)$. O índice possui uma estrutura geral, porém, é calculado especificamente para cada organização. Assim, todas as etapas devem contar com a participação de gestores pertinentes. A estrutura utilizada pelos autores corresponde à estrutura das diretrizes para relatórios de sustentabilidade da GRI (GRI, 2002) e a norma ISO 31 (ISO, 1993) foi utilizada como guia para os termos usados nos nomes e símbolos. No Apêndice 1, há a lista completa desses termos, que também foram utilizados no presente artigo, com base em Kranjc \& Glavič (2005). A hierarquia básica para composição do índice é apresentada na Figura 1 e será discutida na sequência do trabalho.

Todas as etapas do procedimento para calcular o $\mathrm{I}_{\mathrm{CDS}}$ são apresentadas na Figura 2. O primeiro passo para calcular o $\mathrm{I}_{\mathrm{CDS}}$ consiste na seleção dos indicadores apropriados para então agrupá-los nas dimensões econômica, social e ambiental, que são os três aspectos da sustentabilidade (econômico $\mathrm{j}=1$, ambiental, $\mathrm{j}=2$ e social $\mathrm{j}=3$ ).

A seguir, todos os indicadores são segregados em dois grupos: indicadores cujo acréscimo nos resultados causa impacto positivo sob o aspecto da sustentabilidade (I+A) e indicadores cujo acréscimo nos resultados causa impacto negativo sob o aspecto da sustentabilidade (I-A). Por exemplo, um aumento na quantidade de resíduos sólidos gerados por unidade de produção causa um impacto negativo sob a ótica da dimensão ambiental, enquanto que o aumento no percentual de reutilização ou reciclagem de água causa, por seu turno, um impacto positivo.

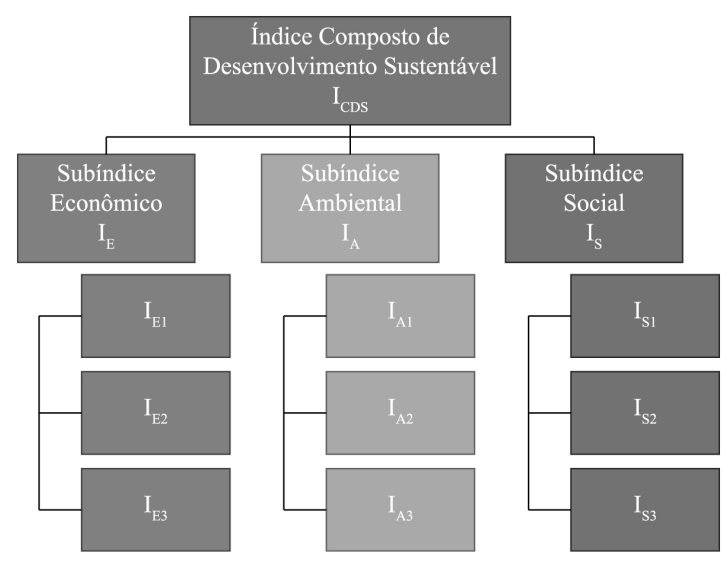

Figura 1. Hierarquia básica para a construção do $\mathrm{I}_{\mathrm{CDS}}$. Fonte: Elaborado com base em Krajnc \& Glavič (2005).

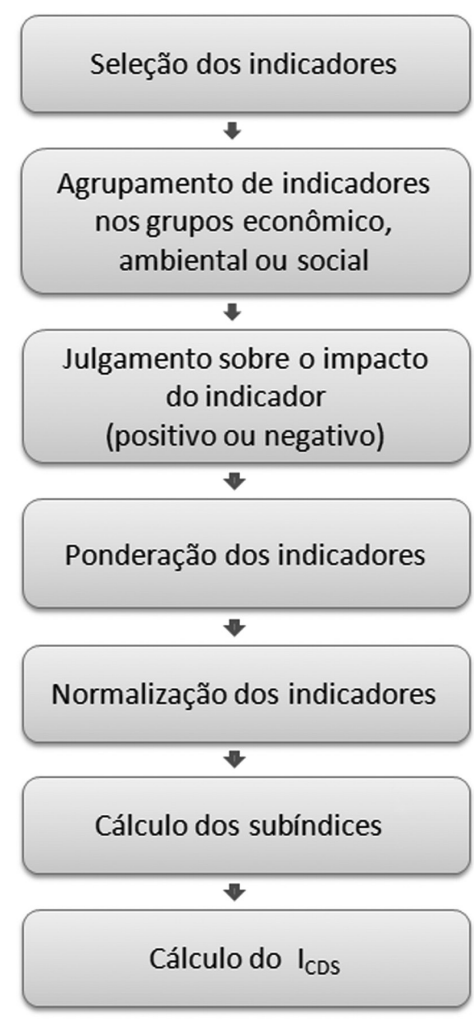

Figura 2. Etapas para a construção do $\mathrm{I}_{\mathrm{CDS}}$. Fonte: Elaborado com base em Krajnc \& Glavič (2005).

Depois do julgamento sobre o impacto de cada indicador, Krajnc \& Glavič (2005) sinalizam que a atribuição de peso aos indicadores deve ser determinada em função da estratégia da empresa. Esta ponderação pode ainda ser realizada em consulta a experts ou ao público em geral, dependendo do tema. Caso a empresa não possua critérios claros para definição da importância dos indicadores dentro da sua estratégia, os autores sugerem utilizar a matriz de comparações pareadas, que é uma ferramenta específica para 
definição de pesos atribuídos a variáveis ou indicadores. As comparações são feitas avaliando-se os indicadores em pares, por meio do seguinte questionamento: "qual dos dois indicadores é mais importante para a empresa em termos de sustentabilidade?"

Assim, a importância ou peso dos indicadores será expressa em uma escala cujos valores encontram-se entre 1 e 9, conforme apresentado no Quadro 1. $O$ valor 1 indica igualdade de importância entre ambos indicadores enquanto que o número 9 expressa uma importância nove vezes maior de um indicador em relação ao que está sendo comparado. Utilizando essa escala, as comparações serão feitas dentro de uma faixa limitada em que a percepção será suficientemente sensível a ponto de se fazer uma distinção. Ao final da avaliação, se o indicador i é "p" vezes a importância do indicador $\mathrm{j}$; então, necessariamente, o indicador $\mathrm{j}$ é " $1 / p$ " vezes a importância do indicador $i$.

Este instrumento é chamado de processo de hierarquia analítica (analytic hierarchy process - AHP) (Saaty, 1980). As comparações pareadas resultam em uma matriz recíproca positiva A. Primeiramente, apenas a primeira coluna da matriz A é fornecida, $\mathrm{i}$. e., a importância relativa dos indicadores $2,3, \ldots$ n, em relação ao indicador 1 . Então o processo de comparação é repetido para cada coluna da matriz, fazendo julgamentos independentes de cada par de indicadores. Ao final das comparações a matriz A está preenchida com todos os pesos relativos.

Uma dificuldade que surge no processo de agregação é o fato de que indicadores possuem diferentes unidades de medida, o que pode tornar o cálculo do índice inviável. Para contornar esse problema, faz-se a normalização dos indicadores, que é a etapa subsequente à ponderação dos indicadores, podendo ser realizada dividindo-se o valor de cada indicador (i) em tempo t (ano) pelo seu valor médio de todos os anos avaliados, conforme apresentado nas Equações 1 e 2.

$$
\begin{gathered}
I_{N, \mathrm{ijt}}^{+}=\frac{I_{A, \mathrm{ijt}}^{+}}{\bar{I}_{A, i j}^{+}} \\
I_{N, \mathrm{ijt}}^{-}=\frac{I_{A, \mathrm{ijt}}^{-}}{\bar{I}_{A, i j}^{-}}
\end{gathered}
$$

Em que $\mathrm{I}_{N, \mathrm{jit}}^{+}$é o indicador i normalizado (com impacto positivo) para o grupo de indicadores $\mathrm{j}$ no tempo $t$ e $\mathrm{I}_{N, \mathrm{ijt}}$ é o indicador i normalizado (com impacto negativo) para o grupo de indicadores $\mathrm{j}$ no tempo $\mathrm{t}$. A normalização de cada indicador também pode ser obtida pela utilização das Equações 3 e 4 .

$$
\begin{gathered}
\mathrm{I}_{N, \mathrm{jit}}^{+}=\frac{\mathrm{I}_{A, \mathrm{jit}}^{+}-\mathrm{I}_{\min , \mathrm{jt}}^{+}}{\mathrm{I}_{\max , \mathrm{jt}}^{+}-\mathrm{I}_{\min , \mathrm{jt}}^{+}} \\
I_{N, \mathrm{ijt}}^{-}=1-\frac{I_{A, \mathrm{jt}}^{-}-I_{\min , \mathrm{jt}}^{-}}{I_{\max , \mathrm{jt}}^{-}-I_{\min , \mathrm{jt}}^{-}}
\end{gathered}
$$

Durante o processo de normalização, os resultados de cada indicador serão reduzidos a uma faixa limitada de flutuação. O método estabelece que o melhor resultado do indicador dentro do histórico avaliado será a nota máxima - 1,000 - possível de ser obtida pela empresa. Da mesma forma, o pior resultado dentro do histórico será a nota mínima-0,000. Assim, os resultados dos subíndices (dimensões econômica, ambiental e social) e do $\mathrm{I}_{\mathrm{CDS}}$ serão gerados com base na comparação do desempenho histórico da própria empresa, pois, o resultado de cada ano será confrontado ao desempenho de todo histórico avaliado. Logo, quanto maior for o histórico existente, maior será o refinamento nos resultados encontrados.

A normalização não será necessária para os casos em que metas específicas forem definidas para cada indicador. Neste caso, a empresa definirá seus objetivos de acordo com sua estratégia e recursos que possui para evoluir rumo à sustentabilidade. Assim, o valor de cada indicador $i$ deve ser dividido no tempo $t$ pela meta definida pela empresa para este indicador. Importante ressaltar que quanto mais desafiadoras forem as metas definidas pela empresa, mais espaço haverá para desenvolvimento e evolução. Se as metas não forem rigorosas a ponto de expressar onde a empresa realmente quer chegar, o índice poderá apresentar um falso desempenho positivo. Assim, sugere-se a utilização de valores de referência internacional como meta para cada indicador.

Os autores alertam ser necessário efetuar a normalização dos indicadores para que possam ser compatibilizados, uma vez que estes irão apresentar

Quadro 1. Escala de Comparação do Processo de Hierarquia Analítica.

\begin{tabular}{|c|l|}
\hline Fator de preferência $\boldsymbol{p}$ & \multicolumn{1}{c|}{ Definição } \\
\hline 1 & Mesma importância entre os dois indicadores \\
\hline 3 & Importância sutilmente maior de um indicador sobre o outro \\
\hline 5 & Importância moderadamente maior de um indicador sobre o outro \\
\hline 7 & Importância visivelmente maior de um indicador sobre o outro \\
\hline 9 & Importância extremamente maior de um indicador sobre o outro \\
\hline $2,4,6,8$ & Valores intermediários \\
\hline Recíproco, $1 / \mathrm{p}$ & Recíproco para comparação inversa \\
\hline
\end{tabular}

Fonte: Hafeez et al. (2002) adaptado pelos autores. 
diferentes unidades de medida. Uma das formas de realizar a normalização é a partir da divisão do valor de cada indicador $(i)$ em tempo $t$ (ano) pelo seu valor médio de todos os anos avaliados. Outro método é pela utilização de valores máximos e mínimos para cada indicador, em que os resultados de cada indicador são reduzidos a uma faixa limitada de flutuação. A normalização não será necessária para os casos em que metas específicas forem definidas para cada indicador.

Depois de obter a matriz de pesos e os valores normalizados para cada indicador, torna-se possível a derivação dos subíndices de sustentabilidade conforme apresentado na Equação 5. O cálculo reúne todos os indicadores básicos de uma dimensão para encontrar os três subíndices propostos.

$$
I_{S, j t}=\sum_{j i t}^{n} \mathrm{~W}_{j i} \cdot I_{N, j i t}^{+}+\sum_{j i t}^{n} \mathrm{~W}_{j i} \cdot I_{N, j i t}^{-}
$$

Na Equação 5, $\mathrm{I}_{S, j t}$ é o subíndice do TBL para o grupo de indicadores $\mathrm{j}$ (econômicos, $\mathrm{j}=1$, ambiental, $\mathrm{j}=2$, social, $\mathrm{j}=3$ ) no tempo $\mathrm{t}$ (em anos) e Wji é o peso do indicador i para o grupo de indicadores $\mathrm{j}$ de DS e reflete a importância desse indicador na avaliação de DS da empresa. Na Equação 6, finalmente, os subíndices são combinados para formar o índice composto em desenvolvimento sustentável $\mathrm{I}_{\mathrm{CDS}}$.

$$
I_{C D S, t}=\sum_{j t}^{n} \mathrm{~W}_{j} \cdot I_{S, j t}
$$

$\mathrm{Na}$ Equação 6, Wj indica o fator representando um peso dado ao grupo $\mathrm{j}$ de indicadores. Estes pesos refletem as prioridades definidas pelos tomadores de decisão da empresa, ou seja, a importância que cada tema terá dentro da estratégia da organização.

\subsection{Cálculo do $\mathrm{I}_{\mathrm{CDS}}$ na Braskem S.A.}

Atualmente, a empresa utiliza uma série de diferentes indicadores para acompanhar o desempenho dos processos internos. Entretanto, apenas indicadores reportados pela empresa no padrão GRI (2012) foram selecionados para o cálculo do índice de sustentabilidade. Estes indicadores são apresentados nos Quadros 2, 3 e 4, respectivamente para os indicadores nas dimensões econômica, ambiental e social.

\begin{tabular}{|c|c|c|c|c|}
\hline Indicadores Econômicos & GRI & Unidade & Símbolo & Impacto (+/-) \\
\hline Ebitda* & $\mathrm{EC} 1$ & $\mathrm{BI} \mathrm{R} \$$ & EBIT & Positivo \\
\hline Investimentos & EC1 & MM R\$ & INVEST & Positivo \\
\hline Valor econômico direto gerado & EC1 & MM R\$ & VAL $_{\text {GER }}$ & Positivo \\
\hline Valor econômico acumulado & EC1 & MM R\$ & $\mathrm{VAL}_{\text {ACUM }}$ & Positivo \\
\hline Ajuda financeira significativa recebida do governo & EC4 & MM R\$ & $\mathrm{AJ}_{\mathrm{FIN}} \mathrm{REC}$ & Positivo \\
\hline
\end{tabular}

Quadro 2. Indicadores selecionados para a dimensão econômica.

*Ebitda: Earnings Before Interest, Taxes, Depreciation and Amortization. Unidades: BI R\$: bilhões de Reais; MM RS: milhões de Reais.

\begin{tabular}{|c|c|c|c|c|}
\hline Indicadores Ambientais & GRI & Unidade & Símbolo & Impacto (+/-) \\
\hline Valor monetário de multas significativas & EN28 & MM R\$ & MULTAS $_{\text {SIG }}$ & Negativo \\
\hline Consumo total de energia primária & EN3 & GJ & $\mathrm{E}_{\text {тот }}$ & Negativo \\
\hline Taxa de energia & EN3 & $\mathrm{GJ} / \mathrm{t}$ prod & $\mathrm{E}_{\mathrm{TX}}$ & Negativo \\
\hline Emissão de GEE (escopo 1) & EN16 & $\mathrm{tCO}_{2} \mathrm{eq}$ & $\mathrm{GEE}_{\text {тот }}$ & Negativo \\
\hline $\mathrm{N}^{\mathrm{o}}$. de derramamentos significativos & EN23 & Unidade & DERR $_{\text {NUM }}$ & Negativo \\
\hline Volume de derramamentos significativos & EN23 & $\mathrm{m}^{3}$ & DERR $_{\text {VOL }}$ & Negativo \\
\hline Percentual de água reciclada/reutilizada & EN10 & $\%$ & $\mathrm{H}_{2} \mathrm{O}_{\%, \mathrm{REC}}$ & Positivo \\
\hline Taxa de água & EN8 & $\mathrm{m}^{3} / \mathrm{t}$ prod & $\mathrm{H}_{2} 0_{\mathrm{TX}}$ & Negativo \\
\hline Consumo de água & EN8 & $\mathrm{m}^{3}$ & $\mathrm{H}_{2} \mathrm{O}_{\text {тот }}$ & Negativo \\
\hline Investimentos e gastos em proteção ambiental & EN30 & MM R\$ & $\mathrm{INV}_{\text {PROT AMB }}$ & Positivo \\
\hline Geração total de resíduos sólidos & EN22 & $\mathrm{Kg}$ & $\mathrm{RES}_{\text {тот }}$ & Negativo \\
\hline Taxa de resíduos & EN22 & $\mathrm{Kg} / \mathrm{t}$ prod & RES $_{\mathrm{TX}}$ & Negativo \\
\hline Geração total de efluentes líquidos & EN21 & $\mathrm{m}^{3}$ & $\mathrm{EFL}_{\text {тот }}$ & Negativo \\
\hline Taxa de efluentes & EN21 & $\mathrm{m}^{3} / \mathrm{t}$ prod & $\mathrm{EFL}_{\mathrm{TX}}$ & Negativo \\
\hline
\end{tabular}

Quadro 3. Indicadores selecionados para a dimensão ambiental.

Unidades: MM R \$: milhões de Reais; GJ: Gigajoules; t prod - toneladas de produto produzido; $\mathrm{CCO}_{2}$ eq - tonelada de $\mathrm{CO}_{2}$ equivalente; $\mathrm{m}^{3}$ - metro cúbico; $\mathrm{m}^{3} /$ ton prod metro cúbico por tonelada produzida; $\mathrm{kg}$ - quilo; $\mathrm{kg} /$ ton prod metro cúbico por tonelada produzida. 
Quadro 4. Indicadores selecionados para a dimensão social.

\begin{tabular}{|c|c|c|c|c|}
\hline Indicadores Sociais & GRI & Unidade & Símbolo & $\operatorname{Impacto}(+/-)$ \\
\hline Total de integrantes & LA1 & Unidade & INT $_{\text {TOT }}$ & Positivo \\
\hline Total de terceirizados & LA1 & Unidade & TER $_{\text {Tот }}$ & Positivo \\
\hline Casos de discriminação & HR4 & Unidade & DISC & Negativo \\
\hline Proporção da remuneração entre homens e mulheres (líderes) & LA14 & - & $\mathrm{REM}_{\mathrm{HM}}$ & Negativo \\
\hline Taxa de absenteísmo & LA7 & $*$ & $\mathrm{ABS}_{\mathrm{TX}}$ & Negativo \\
\hline Taxa de frequência de acidentes $(\mathrm{CAF}+\mathrm{SAF})$ & LA7 & $* *$ & $\mathrm{AC}_{\mathrm{TOT}}{ }_{\mathrm{TX}}$ & Negativo \\
\hline $\mathrm{N}^{\mathrm{o}}$. de acidentes sem afastamento & LA7 & Unidade & $\mathrm{AC}_{\mathrm{TOT}, \mathrm{SAF}}$ & Negativo \\
\hline $\mathrm{N}^{\circ}$. de acidentes com afastamento & LA7 & Unidade & $\mathrm{AC}_{\text {TOT, CAF }}$ & Negativo \\
\hline Taxa de Gravidade de acidentes & LA7 & $* * *$ & GRAV $_{\mathrm{TX}}$ & Negativo \\
\hline $\mathrm{N}^{\mathrm{o}}$. de doenças ocupacionais & LA7 & Unidade & $\mathrm{DO}_{\mathrm{TOT}}$ & Negativo \\
\hline Óbitos & LA7 & Unidade & OBIT & Negativo \\
\hline Investimentos em SSMA & HR1 & MM R\$ & $\mathrm{INV}_{\text {SSMA }}$ & Positivo \\
\hline
\end{tabular}

*ABS $\mathrm{TX}_{\mathrm{TX}}-\mathrm{N}^{\circ}$ de horas faltadas / HHT x 100. **AC ${ }_{\mathrm{TOT}, \mathrm{TX}}-\mathrm{N}^{\circ}$ acidentes / HHT x 1 milhão. *** $\mathrm{GRAV}_{\mathrm{TX}}-\left(\mathrm{N}^{\circ}\right.$ de dias perdidos + debitados) / HHT x 1 milhão. (Obs.: HHT = homem hora de trabalho; SSMA = Saúde, Segurança e Meio Ambiente).

Os indicadores da dimensão econômica do tipo EC1 buscam refletir aspectos relacionados ao desempenho financeiro, como lucratividade, e aspectos de natureza econômica, principalmente relacionadas ao valor ou riqueza criados. O indicador EC4 busca avaliar se a empresa recebe ajuda financeira do governo, o que pode ser interpretado como um "aval" do governo às atividades da empresa.

Os indicadores da dimensão ambiental buscam cobrir os vários aspectos dos impactos ambientais das atividades da empresa. Em função de sua natureza, retratam principalmente aspectos relacionados ao processo produtivo de extrema relevância em uma indústria do setor petroquímico.

Os indicadores da dimensão social buscam analisar diversas questões mais diretamente relacionadas às pessoas, empregados e comunidade. Tratam de assuntos que vão desde aspectos demográficos, como geração de empregos e participação de terceirizados na composição de mão de obra da empresa (LA1), ou ainda de valorização das minorias, como o LA14, indo até aspectos comportamentais, como o HR4.

Além de selecionar apenas indicadores reportados no relatório anual de desempenho de acordo com o formato GRI, outro critério foi aplicado para a fase de seleção: somente indicadores quantitativos foram elencados. Como o método prevê uma série de equações e cálculos aplicados aos resultados de cada indicador, a utilização de indicadores qualitativos pode, num primeiro momento, tornar o processo ainda mais complexo e subjetivo, dificultando a sua implementação.

A adequação das bases de alguns indicadores foi uma atividade realizada previamente à aplicação do método e ao cálculo do índice. Ao longo dos últimos anos, a Braskem adquiriu alguns ativos nacionais e internacionais e, por conta disso, as bases de reporte dos indicadores não seguiram, necessariamente, $o$ mesmo padrão. Ou seja, alguns resultados incluíam o desempenho das unidades internacionais incorporadas em 2011, enquanto outros não contemplavam nem mesmo os ativos adquiridos no Brasil durante o ano de 2010. Depois de definir-se pela utilização dos resultados das unidades do Brasil, estes valores foram consolidados, excluindo-se resultados das unidades internacionais. Ao final, conseguiu-se um histórico de resultados desde o ano de 2008. A rastreabilidade para consolidação dos resultados anteriores não foi possível. Os resultados dos indicadores econômicos, ambientais e sociais são apresentados, respectivamente, nas Tabelas 1, 2 e 3.

A atribuição de pesos aos indicadores selecionados - fase de ponderação - considerou os macro-objetivos da Visão 2020 da Braskem. Os sete macro-objetivos, direcionadores da estratégia da Braskem até o ano de 2020, são relacionados a: segurança química, gases de efeito estufa, eficiência hídrica, eficiência energética, matéria-prima renovável, pós-consumo e pessoas. Como critério, um peso dobrado foi atribuído a todos os indicadores diretamente relacionados aos macro-objetivos da visão da Braskem para o cálculo do índice.

Nas Tabelas 4, 5 e 6, são apresentados os resultados normalizados dos indicadores para as dimensões econômica, ambiental e social respectivamente, já considerando os pesos definidos na fase de ponderação. Conforme definido pelo método, para cada indicador, dentro do período avaliado, foi designado um resultado máximo $(1,000)$ e um resultado mínimo $(0,000)$. Os demais resultados flutuarão entre estes dois valores de acordo com o desempenho de cada ano. Este método foi selecionado, pois permite que os resultados dos subíndices (dimensões econômica, ambiental e social) e do $\mathrm{I}_{\mathrm{CDS}}$ sejam gerados com base 
Tabela 1. Resultados dos indicadores econômicos.

\begin{tabular}{lccccc}
\hline \multicolumn{1}{c}{ Símbolo } & Unidade & $\mathbf{2 0 0 8}$ & $\mathbf{2 0 0 9}$ & $\mathbf{2 0 1 0}$ & $\mathbf{2 0 1 1}$ \\
\hline EBIT & BI R $\$$ & 2,5 & 3,2 & 4,1 & 3,7 \\
INVEST & MM R\$ & 1.394 & 894 & 1.800 & 2.078 \\
VAL $_{\text {GER }}$ & MM R\$ & 17.960 & 16.136 & 25.495 & 33.176 \\
VAL $_{\text {DIST }}$ & MM R $\$$ & 20.659 & -15.977 & -25.825 & -35.118 \\
VAL $_{\text {ACUM }}$ & MM R\$ & -2.700 & 839 & -330 & -1.942 \\
AJ FIN $_{\text {REC }}$ & MM R\$ & 77,5 & 107,7 & 21,3 & 45,9 \\
\hline
\end{tabular}

Tabela 2. Resultados dos indicadores ambientais.

\begin{tabular}{|c|c|c|c|c|c|}
\hline Símbolo & Unidade & 2008 & 2009 & 2010 & 2011 \\
\hline MULTAS $_{\text {SIG }}$ & MM RS & 0 & 0 & 0 & 0,583 \\
\hline $\mathrm{E}_{\text {тот }}$ & GJ & 167.065 .784 & 166.231 .521 & 164.107 .110 & 158.144 .299 \\
\hline $\mathrm{E}_{\mathrm{TX}}$ & $\mathrm{GJ} / \mathrm{t}$ produto & 12,35 & 11,71 & 11,07 & 11,34 \\
\hline $\mathrm{GEE}_{\text {тот }}$ & $\mathrm{tCO}_{2} \mathrm{eq}$ & 7.545 .365 & 9.369 .780 & 9.233 .667 & 8.911 .771 \\
\hline DERR $_{\text {NUM }}$ & Unidade & 1 & 0 & 2 & 6 \\
\hline DERR $_{\text {voL }}$ & $\mathrm{m}^{3}$ & 0,08 & 0 & 1,3 & 12,5 \\
\hline $\mathrm{H}_{2} \mathrm{O}_{\%, \mathrm{REC}}$ & $\%$ & 2,9 & 2,9 & 20,7 & 18,49 \\
\hline $\mathrm{H}_{2} \mathrm{O}_{\mathrm{TX}}$ & $\mathrm{m}^{3} / \mathrm{t}$ prod & 4,65 & 3,92 & 4,23 & 4,65 \\
\hline $\mathrm{H}_{2} \mathrm{O}_{\text {тот }}$ & $\mathrm{m}^{3}$ & 50.294 .184 & 43.058 .737 & 62.701 .075 & 64.837 .645 \\
\hline $\mathrm{INV}_{\text {PROT AMB }}$ & MM R\$ & 143,99 & 200,22 & 245,04 & 298,51 \\
\hline $\operatorname{RES}_{\text {тот }}$ & $\mathrm{Kg}$ & 47.054 .260 & 34.748 .281 & 33.304 .118 & 30.522 .437 \\
\hline RES $_{\mathrm{TX}}$ & $\mathrm{Kg} / \mathrm{t}$ prod & 3,48 & 2,45 & 2,25 & 2,19 \\
\hline $\mathrm{EFL}_{\text {тот }}$ & $\mathrm{m}^{3}$ & 19.556 .126 & 20.039 .275 & 18.154 .037 & 17.596 .026 \\
\hline $\mathrm{EFL}_{\mathrm{TX}}$ & $\mathrm{m}^{3} / \mathrm{t}$ prod & 1,45 & 1,41 & 1,22 & 1,26 \\
\hline
\end{tabular}

Tabela 3. Resultados dos indicadores sociais.

\begin{tabular}{|c|c|c|c|c|c|}
\hline Símbolo & Unidade & 2008 & 2009 & 2010 & 2011 \\
\hline $\mathrm{INT}_{\text {тот }}$ & Unidade & 4.764 & 4.531 & 6.222 & 6.477 \\
\hline $\mathrm{TER}_{\text {тот }}$ & Unidade & 26.279 & 15.946 & 22.096 & 27.714 \\
\hline DISC & Unidade & 2 & 1 & 1 & 0 \\
\hline $\mathrm{REM}_{\mathrm{HM}}$ & - & 1,3 & 1,14 & 1,18 & 1,13 \\
\hline $\mathrm{ABS}_{\mathrm{TX}}$ & $*$ & 0,028 & 0,073 & 0,041 & 0,026 \\
\hline $\mathrm{AC}_{\text {тот, тХ }}$ & $* *$ & 6,15 & 4,68 & 1,89 & 1,14 \\
\hline $\mathrm{AC}_{\mathrm{TOT}, \mathrm{SAF}}$ & Unidade & 349 & 152 & 57 & 30 \\
\hline $\mathrm{AC}_{\mathrm{TOT}, \mathrm{CAF}}$ & Unidade & 41 & 43 & 26 & 27 \\
\hline GRAV $_{\mathrm{TX}}$ & $* * *$ & 27,42 & 52,28 & 253,04 & 55,9 \\
\hline $\mathrm{DO}_{\text {Tот }}$ & Unidade & 1 & 3 & 1 & 0 \\
\hline OBIT & Unidade & 0 & 0 & 1 & 0 \\
\hline $\mathrm{INV}_{\text {SSMA }}$ & MM R\$ & 161 & 102 & 167 & 151 \\
\hline
\end{tabular}

na comparação do desempenho histórico da própria empresa. Esta comparação proporcionará maior refinamento nos resultados encontrados, quanto maior for o histórico existente.

Depois de ponderar e normalizar todos os indicadores selecionados, foram realizados os cálculos para obtenção dos subíndices e do $\mathrm{I}_{\mathrm{CDS}}$, conforme apresentado na Tabela 7. Nesta etapa, a visão da Braskem também foi considerada para atribuição da importância que cada dimensão terá no peso final do índice. Ou seja, a participação de cada dimensão na ponderação final do índice será diretamente proporcional à sua relevância 
Tabela 4. Ponderação e normalização dos indicadores econômicos.

\begin{tabular}{lcccccc}
\hline Abreviatura & Peso Absoluto & Peso Relativo & $\mathbf{2 0 0 8}$ & $\mathbf{2 0 0 9}$ & $\mathbf{2 0 1 0}$ & $\mathbf{2 0 1 1}$ \\
\hline EBIT & 1 & 0,200 & 0,000 & 0,375 & 1,000 & 0,750 \\
INVEST & 1 & 0,200 & 0,422 & 0,000 & 0,765 & 1,000 \\
VAL $_{\text {GER }}$ & 1 & 0,200 & 0,107 & 0,000 & 0,549 & 1,000 \\
VAL $_{\text {ACUM }}$ & 1 & 0,200 & 0,000 & 1,000 & 0,670 & 0,214 \\
AJ FIN $_{\text {REC }}$ & 1 & 0,200 & 0,650 & 1,000 & 0,000 & 0,285 \\
\hline
\end{tabular}

Tabela 5. Ponderação e normalização dos indicadores ambientais.

\begin{tabular}{|c|c|c|c|c|c|c|}
\hline Abreviatura & Peso Absoluto & Peso Relativo & 2008 & 2009 & 2010 & 2011 \\
\hline MULTAS $_{\text {SIG }}$ & 1 & 0,045 & 1,000 & 1,000 & 1,000 & 0,000 \\
\hline $\mathrm{E}_{\text {тот }}$ & 2 & 0,091 & 0,000 & 0,094 & 0,332 & 1,000 \\
\hline $\mathrm{E}_{\mathrm{TX}}$ & 2 & 0,091 & 0,000 & 0,500 & 1,000 & 0,789 \\
\hline $\mathrm{GEE}_{\text {тот }}$ & 2 & 0,091 & 1,000 & 0,000 & 0,075 & 0,251 \\
\hline DERR $_{\text {NUM }}$ & 1 & 0,045 & 0,833 & 1,000 & 0,667 & 0,000 \\
\hline DERR $_{\text {VOL }}$ & 1 & 0,045 & 0,994 & 1,000 & 0,896 & 0,000 \\
\hline $\mathrm{H}_{2} \mathrm{O}_{\%, \mathrm{REC}}$ & 2 & 0,091 & 0,000 & 0,000 & 1,000 & 0,876 \\
\hline $\mathrm{H}_{2} 0_{\mathrm{TX}}$ & 2 & 0,091 & 0,000 & 1,000 & 0,575 & 0,000 \\
\hline $\mathrm{H}_{2}{ }$ тот & 2 & 0,091 & 0,668 & 1,000 & 0,098 & 0,000 \\
\hline $\mathrm{INV}_{\text {РROT АМВ }}$ & 1 & 0,045 & 0,000 & 0,364 & 0,654 & 1,000 \\
\hline $\operatorname{RES}_{\text {тот }}$ & 2 & 0,091 & 0,000 & 0,744 & 0,798 & 1,000 \\
\hline RES $_{\mathrm{TX}}$ & 2 & 0,091 & 0,000 & 0,798 & 0,953 & 1,000 \\
\hline $\mathrm{EFL}_{\text {тот }}$ & 1 & 0,045 & 0,198 & 0,000 & 0,772 & 1,000 \\
\hline $\mathrm{EFL}_{\mathrm{TX}}$ & 1 & 0,045 & 0,000 & 0,174 & 1,000 & 0,826 \\
\hline
\end{tabular}

Tabela 6. Ponderação e normalização dos indicadores sociais.

\begin{tabular}{lcccccc}
\hline \multicolumn{1}{c}{ Indicador } & Peso Absoluto & Peso Relativo & $\mathbf{2 0 0 8}$ & $\mathbf{2 0 0 9}$ & $\mathbf{2 0 1 0}$ & $\mathbf{2 0 1 1}$ \\
\hline $\mathrm{INT}_{\text {тот }}$ & 1 & 0,050 & 0,120 & 0,000 & 0,869 & 1,000 \\
$\mathrm{TER}_{\text {тот }}$ & 1 & 0,050 & 0,878 & 0,000 & 0,523 & 1,000 \\
$\mathrm{DISC}$ & 2 & 0,100 & 0,000 & 0,500 & 0,500 & 1,000 \\
$\mathrm{REM}_{\text {нм }}$ & 1 & 0,050 & 0,000 & 0,941 & 0,706 & 1,000 \\
$\mathrm{ABS}_{\text {Tх }}$ & 2 & 0,100 & 0,957 & 0,000 & 0,681 & 1,000 \\
$\mathrm{AC}_{\text {тот } \text { тх }}$ & 2 & 0,100 & 0,000 & 0,293 & 0,850 & 1,000 \\
$\mathrm{AC}_{\text {тот, ААF }}$ & 2 & 0,100 & 0,000 & 0,618 & 0,915 & 1,000 \\
$\mathrm{AC}_{\text {тот, САF }}$ & 2 & 0,100 & 0,118 & 0,000 & 1,000 & 0,941 \\
GRAV $_{\text {тх }}$ & 2 & 0,100 & 1,000 & 0,890 & 0,000 & 0,874 \\
DO $_{\text {тот }}$ & 2 & 0,100 & 0,667 & 0,000 & 0,667 & 1,000 \\
OBIT & 2 & 0,100 & 1,000 & 1,000 & 0,000 & 1,000 \\
INV $_{\text {SSMA }}$ & 1 & 0,050 & 0,908 & 0,000 & 1,000 & 0,754 \\
\hline
\end{tabular}

dentro da visão da empresa. Dessa forma, os pesos 0,5, 0,3 e 0,2 foram aplicados, respectivamente, aos subíndices ambiental, social e econômico, de acordo com o estabelecido pela estratégia da empresa.

\section{Discussão}

A metodologia descrita no trabalho e aplicada aos resultados históricos da Braskem, além de se apresentar como uma ferramenta de fácil utilização alcançou seu objetivo proposto - avaliar o desempenho de uma empresa em sustentabilidade por meio de um índice único. O método pode ser considerado flexível e, bem por isso, se acredita que pode ser aplicado em empresas com diferentes objetivos, ramos de atuação e dimensões.

Essa flexibilidade permite a modificação das variáveis estudadas, i.e., com a seleção e ponderação de indicadores; a aplicação em unidades isoladas ou dos resultados consolidados de toda a empresa; a diferenciação da importância que cada dimensão terá 
Tabela 7. Resultados dos subíndices e do $\mathrm{I}_{\mathrm{CDS}}$.

\begin{tabular}{lllll}
\hline \multicolumn{1}{c}{ Índices } & $\mathbf{2 0 0 8}$ & $\mathbf{2 0 0 9}$ & $\mathbf{2 0 1 0}$ & $\mathbf{2 0 1 1}$ \\
\hline Subíndice Econômico & 0,236 & 0,475 & 0,597 & 0,650 \\
Subíndice Ambiental & 0,289 & 0,537 & 0,666 & 0,575 \\
Subíndice Social & 0,469 & 0,377 & 0,616 & 0,969 \\
I $_{\text {CDS }}$ (ponderado) & 0,333 & 0,477 & 0,637 & 0,708 \\
\hline
\end{tabular}

dentro do índice; a comparação dos resultados com empresas do mesmo porte ou ramo; o acompanhamento mensal, anual ou de um determinado período definido, dentre outras variáveis. Todos estes elementos devem ser previamente definidos, levando-se em consideração os objetivos para o uso desta ferramenta.

Em relação ao desempenho da Braskem em sustentabilidade, os resultados provenientes da agregação de cinco indicadores econômicos, 14 ambientais e 12 sociais, conforme os critérios impostos pelo método são apresentados no gráfico da Figura 3. Pela análise deste gráfico, percebe-se uma evolução constante e praticamente linear ano após ano nos resultados da Braskem, o que pode evidenciar um aumento regular nas taxas de esforço e recursos disponibilizados pela empresa na busca de seus objetivos, rumo à sustentabilidade, como definido de forma expressa pela estratégia da empresa. Em relação ao desempenho individual das três dimensões, percebe-se uma evolução muito semelhante em relação aos resultados das dimensões econômica e ambiental em todos os anos. Acredita-se que os resultados da dimensão social não acompanharam a mesma tendência de evolução, pois indicadores que contribuem fortemente para estes resultados, como acidentes, doenças ocupacionais e absenteísmo, tiverem seus piores e melhores resultados, respectivamente nos anos de 2009 e 2011.

Embora tenha sido atribuído maior peso à dimensão ambiental na fase de ponderação dos subíndices, o resultado final do $\mathrm{I}_{\mathrm{CDS}}$ não foi fortemente afetado pela dimensão, pois, em praticamente todos os anos, o resultado dos indicadores ambientais se aproximou muito do valor médio das outras dimensões, com exceção do ano de 2011, para o qual o desempenho ambiental contribuiu negativamente para o resultado final do índice.

A dimensão econômica apresenta um comportamento de crescimento, com exceção do último ano. Quedas significativas nos indicadores Valor econômico direto gerado e Valor econômico acumulado levaram a um desempenho ruim ao final do período.

É interessante notar que, apesar de diferentes resultados em termos individuais das dimensões, o $\mathrm{I}_{\mathrm{CDS}}$ apresenta um comportamento mais estável, com uma tendência crescente. Em outras palavras, um resultado ruim em uma dimensão é "compensado" por um resultado positivo em outra.

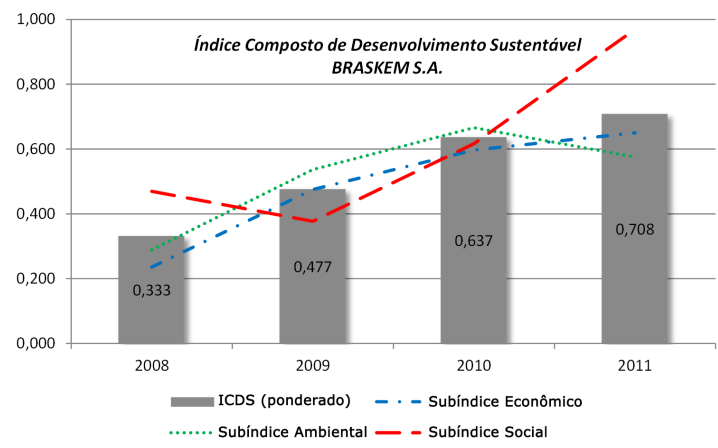

Figura 3. Série histórica do desempenho do $\mathrm{I}_{\mathrm{CDS}}$ da Braskem. Fonte: Elaborado pelos autores.

\section{Considerações finais}

\subsection{Implicações de ordem conceitual}

A necessidade de se mensurar e analisar o desempenho das empresas não é um tema novo. No entanto, devido a sua complexidade, as iniciativas de gerenciar o desempenho relacionado à temática da sustentabilidade têm requerido inúmeros esforços, tanto no meio acadêmico, quanto nas próprias empresas. Neste trabalho, por meio de uma aplicação adaptada do modelo de Krajnc \& Glavič (2005), percebeu-se que, além de fornecer números parciais de desempenho para cada dimensão avaliada, a ferramenta apresentou grande flexibilidade nas etapas de seleção, ponderação e normalização dos indicadores, conferindo versatilidade para aplicação em diferentes situações.

Assim, do ponto de vista acadêmico, evidenciou-se o vigor do modelo e do ponto de vista prático, sua aplicabilidade, como será discutido adiante. Além disso, durante a aplicação no caso da empresa analisada, percebeu-se, pelas discussões, a importância e a necessidade de modelos e ferramentas sistêmicas e integradas, em função da natureza da mensuração do desempenho da empresa no que se refere à sustentabilidade, em suas diferentes dimensões.

Muito embora haja tal proliferação de estudos, afirma-se que há problemas conceituais e de medidas não resolvidos adequadamente pelas experiências em curso (Vinodh, 2011). Como principais dificuldades observadas na mensuração de sustentabilidade é possível citar a inexistência de uma base de dados histórica acerca de informações provenientes de 
indicadores de sustentabilidade, a dificuldade na definição de expressões matemáticas condizentes aos parâmetros selecionados, a perda de informação nos processos de agregação de dados, os diferentes critérios utilizados e a falta de consolidação quando da seleção de indicadores (Callado \& Fensterseifer, 2011), entre diferentes organizações. Espera-se que o índice criado por Kranjc \& Glavič (2005) permita aplicações em diferentes contextos que o original, reafirmando sua robustez e pertinência enquanto ferramenta de avaliação integrada do desempenho organizacional em direção à sustentabilidade. Além disso, com a aplicação de um instrumento já validado cientificamente, almeja-se apontar possíveis limitações e oportunidades de aprimoramentos, avançando na consolidação do conhecimento empírico na área.

\subsection{Implicações de ordem prática}

O trabalho ilustra que é possível avaliar a sustentabilidade organizacional de uma forma integrada que possa fornecer uma boa orientação para a tomada de decisão gerencial. O modelo apresentado possibilita a avaliação da sustentabilidade das empresas e faz com que informações de sustentabilidade sejam mais úteis, de fato, uma vez que se trata de um conceito de difícil compreensão para os tomadores de decisão. Além disso, devido à sua flexibilidade, pode ser adaptado a diferentes empresas, com diferentes estratégias e, que, portanto, demandam instrumentos de sustentabilidade que possam refletir seu contexto específico.

Assim, o objetivo do $\mathrm{I}_{\mathrm{CSD}}$ é dar tanto uma expressão simplificada quanto quantificada por uma composição complexa de vários indicadores. No entanto, ele pode - e deve - ser incluído em um contexto mais amplo, estratégico, como refletindo o status da empresa em relação à sustentabilidade, não só no monitoramento, mas também como base para uma empresa orientada para a sustentabilidade. Além disso, se incluído e desenvolvido em consonância com o relatório anual

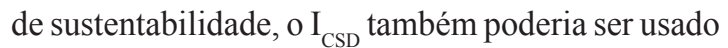
para apresentar o progresso da empresa para as várias partes interessadas e até possibilitaria, guardadas as diferenças inerentes ao processo, uma comparação e classificação de empresas do setor.

Como verificado no caso da Braskem, o modelo ajuda a destacar as oportunidades de melhoria e onde as melhores práticas podem ser identificadas e replicadas. O I $\mathrm{I}_{\mathrm{CSD}}$ configura, dessa forma, um importante subsídio para tomada de decisão voltada à temática da sustentabilidade.

\subsection{Limitações do estudo e pesquisas futuras}

Uma possível limitação do modelo utilizado neste trabalho pode estar relacionada ao modo como os pesos de indicadores são determinados, de forma complexa, imprecisa e talvez subjetiva. Pode-se argumentar que os pesos utilizados refletem hierarquias e/ou prioridades, de acordo com a opinião dos decisores e podem, por conseguinte, sofrer de um alto grau de subjetividade. No entanto, no caso de diferentes opiniões sobre a importância de um indicador, não é necessário reformular o modelo proposto, mas apenas reavaliar os pesos atribuídos para futuras aplicações. Caberia, aqui, talvez um estudo com foco em desenvolver uma metodologia para definição dos pesos dos indicadores, possivelmente com inclusões de diferentes pontos de vista, que abrangessem, além da alta administração, os trabalhadores de outros níveis hierárquicos, algo que poderia gerar visões diferenciadas.

Devido à limitação do escopo do trabalho, não foi feita uma análise das causas que levaram aos resultados apresentados pelo $\mathrm{I}_{\mathrm{CDS}}$ e cada um de seus subíndices e indicadores, uma vez que o objetivo do trabalho voltou-se à aplicação do modelo.

Outra limitação a ser apontada refere-se às possíveis influências externas incidentes sobre os indicadores do desempenho da sustentabilidade avaliados na Braskem. É plausível que, ao longo dos anos considerados no estudo, ocorrências fora dos domínios internos da organização, como os setoriais, econômicos e sociais, possam ter afetado o resultado dos indicadores e, com isso, refletido nos resultados do $\mathrm{I}_{\mathrm{CDS} \text {. }}$ São ocorrências, no entanto, improváveis de serem captadas por um índice desta natureza, ou seja, caracterizando uma limitação da própria metodologia, que tem por foco principal o ambiente intraorganizacional.

A título de novas pesquisas, sugere-se, além da aplicação do modelo proposto em diferentes contextos e empresas, uma discussão sobre novas tentativas de se definir e mensurar a sustentabilidade organizacional, a partir de diferentes expectativas quanto à importância da sustentabilidade na estratégia das empresas. No caso aqui analisado, a sustentabilidade mostra-se crítica tanto para a empresa quanto para o próprio setor; caberia investigar qual seria o quadro em outras realidades.

Sugere-se ainda que, em estudos futuros, os resultados da aplicação do $\mathrm{I}_{\mathrm{CDS}}$ - tanto no contexto desta pesquisa quanto em outros - seja complementada com a percepção de gestores sobre a evolução da sustentabilidade na empresa em análise, assim como com outros documentos, tais quais relatórios integrados de sustentabilidade. Dessa forma, as discussões poderiam ser amplificadas e enriquecidas à medida que diferentes fontes de informação fossem confrontadas.

\section{Referências}

Associação Brasileira da Indústria Química-ABIQUIM. (2013). A indústria química brasileira. Recuperado em 12 de agosto de 2012, de http://www.abiquim.org.br/ pdf/indQuimica/AIndustriaQuimica-SobreSetor.pdf 
Azapagic, A. (2004). Developing a framework for sustainable development indicators for the mining and minerals industry. Journal of Cleaner Production, 12(6), 639662. http://dx.doi.org/10.1016/S0959-6526(03)00075-1.

Barkemeyer, R., Holt, D., Preuss, L., \& Tsang, S. (2014). What happened to the 'Development' in sustainable development? Business guidelines two decades after brundtland. Sustainable Development, 22(1), 15-32. http://dx.doi.org/10.1002/sd.521.

BRASKEM. (2011). Relatório Anual 2011. Recuperado em 1 de agosto de 2012, de http://rao2011.braskem. com.br/pdf/RA2011_braskem_pt.pdf

BRASKEM. (2012). Relatório de Sustentabilidade 2012. Recuperado em 12 de dezembro de 2013, de http:// www.grao2012.braskem.com/Default.asp?idioma=pt

BRASKEM. (2013). Braskem website. Recuperado em 12 de agosto de 2012, de www.braskem.com.br

Callado, A. L. C., \& Fensterseifer, J. E. (2011). Corporate sustainability measure from an integrated perspective: the Corporate Sustainability Grid (CSG). International Journal of Business Insights and Transformation, 3, 44-53.

Conselho Empresarial Brasileiro para o Desenvolvimento Sustentável-CEBDS. (2007). Relatório de sustentabilidade empresarial. Rio de Janeiro: CEBDS.

Doppelt, B. (2008). The power of sustainable thinking: how to create a positive future for the climate, the planet, your organization and your life. London: Earthscan.

Dyllick, T., \& Hockerts, K. (2002). Beyound the business case for corporate sustentability. Business Strategy and the Environment, 11(2), 130-141. http://dx.doi. org/10.1002/bse.323.

Elkington, J. (1999). Cannibals with forks: the triple bottom line of 21st century business. Oxford: Capstone Publishing Limited.

Epstein, M. J. (2008). Making sustainability work: best practices in managing and measuring corporate social, environmental, and economic impacts. Sheffield: Greenleaf Publishing Limited.

European Chemical Industry Council - CEFIC. (2012). Facts and figures 2012: the European chemicals industry in a worldwide perspective. Recuperado em 6 de agosto de 2012, de http:/www.cefic.org/Documents/ FactsAndFigures/2012/Facts-and-Figures-2012-TheBrochure.pdf

Furtado, J. S. (2005). Sustentabilidade empresarial: guia de práticas econômicas, ambientais e sociais. Salvador: NEAMA/CRA.

García-Serna, J., Pérez-Barrigón, L., \& Cocero, M. J. (2007). New trends for design towards sustainability in chemical engineering: Green engineering. Chemical Engineering Journal, 133(1-3), 7-30. http://dx.doi. org/10.1016/j.cej.2007.02.028.

Global Reporting Initiative-GRI. (2002). Sustainability Reporting Guidelines 2002 on Economic, Environmental and Social Performance (Global Reporting Initiative).
Recuperado em 20 de março de 2011, de http://www. globalreporting.org, 2002.

Global Reporting Initiative - GRI. (2012). Elaboração de relatórios de sustentabilidade. Recuperado em 15 de junho de 2012, de https://www.globalreporting.org/languages/ Portuguesebrazil/Pages/Elabora \%c3\%a7\%c3\%a3o-derelat $\%$ c3\%b3rios-de-sustentabilidade.aspx

Guttenstein, E., El-Hage Scialabba, N., Loh, J., \& Courville, S. (2010). A conceptional framework for progressing towards sustainability in the agriculture and food sector (Alliance Discussion Paper, pp. 1-24). Holanda: FAO/ ISEALAlliance. Recuperado em 20 de março de 2011, de www.fao.org/docrep/012/al322e/al322e00.pdf.

Hacking, T., \& Guthrie, P. (2008). A framework for clarifying the meaning of the triple bottom-line, integrated, and sustainability assessment. Environmental Impact Assessment Review, 28(2-3), 73-89. http://dx.doi. org/10.1016/j.eiar.2007.03.002.

Hafeez, K., Zhang, Y., \& Malak, N. (2002). Determining key capabilities of a firm using analytic hierarchy process. International Journal of Production Economics, 76(1), 39-51. http://dx.doi.org/10.1016/S0925-5273(01)00141-4.

Hahn, T., \& Scheermesser, M. (2006). Approaches to corporate sustainability among German companies. Corporate Social Responsibility and Environmental Management, 13(3), 121-181. http://dx.doi.org/10.1002/ csr. 100.

Hák, T., Moldan, B., \& Dahl, A. L. (Ed.). (2007). Sustainability indicators: a scientific assessment. Washington: Island Press.

Hall, G. M., \& Howe, J. (2010). Sustainability of the chemical manufacturing industry - towards a new paradigm? Education for Chemical Engineers, 5(4), 100-107. http://dx.doi.org/10.1016/j.ece.2010.09.001.

Hammond, A., Adriaanse, A., Rodenburg, E., Bryant, D., \& Woodward, E. (1995). Environmental indicators: a systematic approach to measuring and reporting on environmental policy performance in the context of sustainable development. Washington: World Resources Institute.

Infante, C. E. D. D. C., Mendonça, F. M., Purcidonio, P. M., \& Valle, R. (2013). Triple bottom line analysis of oil and gas industry with multicriteria decision making. Journal of Cleaner Production, 52, 289-300. http:// dx.doi.org/10.1016/j.jclepro.2013.02.037.

Instituto Brasileiro de Análises Sociais - IBASE. (2012). Balanço social IBASE. Recuperado em 6 de agosto de 2012, de http://www.ibase.br

Instituto Ethos. (2008). Indicadores Ethos de responsabilidade social empresarial. Recuperado em 20 de maio de 2008, de http://www.ethos.org.br/docs/conceitos_praticas/ indicadores/default.asp

International Integrated Reporting Council - IIRC. (2013). Business and investors explore the sustainability perspective of integrated reporting: IIRC pilot programme yearbook 2013 (Integrated Reporting, pp. 1-48). IIRC. 
International Organization for Standardization - ISO. (1993). Quantities and units, ISO standards handbook. Geneve: ISO.

Kleizen, H. H. (2006). Conceptual chemical process design in a sustainable technological world. Journal of Cleaner Production, 14(9-11), 924-927. http://dx.doi. org/10.1016/j.jclepro.2005.11.035.

Krajnc, D., \& Glavič, P. (2005). A model for integrated assessment of sustainable development. Resources, Conservation and Recycling, 43(2), 189-208. http:// dx.doi.org/10.1016/S0921-3449(04)00120-X.

Leite e Filho, G. A., Prates, L. A., \& Guimarães, T. N. (2009). Níveis de evidenciação dos relatórios de sustentabilidade das empresas brasileiras a+ do Global Reporting Initiative (GRI) no ano de 2007. In Anais do XXXIII Associação Nacional de Pós-Graduação e Pesquisa em Administração. Rio de Janeiro: ANPAD.

Léle, S. (1991). Sustainable development: a critical review. World Development, 19(6), 607-621. http://dx.doi. org/10.1016/0305-750X(91)90197-P.

Majumdar, J., Bhasin, V., \& Jollands, M. (2009). Sustainability tools for the chemical industry. In Proceedings of the VI Australian Conference on Life Cycle Assessment. Melbourne: ALCAS.

Mulderink, J. J. M. (1998). Sustainability in the chemical industry by 2050. Studies in Environmental Science, 72, 909-914. http://dx.doi.org/10.1016/S0166-1116(98)80053-8.

Organisation for Economic Co-operation and Development - OECD. (2003). OECD environmental indicators: development, measurement and use. Recuperado em 30 de março de 2010, de http://www.oecd.org/ dataoecd/7/47/24993546.pdf

Pava, M. L. (2007). A response to "Getting to the bottom of triple bottom line". Business Ethics Quarterly, 17(1), 105-110. http://dx.doi.org/10.5840/beq200717116.

Saaty, T. L. (1980). Analytical hierarchy process: planning, priority setting, resource allocation. NewYork: McGraw-Hill.

Savitz, A. W., \& Weber, K. (2007). A empresa sustentável: o verdadeiro sucesso é lucro com responsabilidade social e ambiental. Rio de Janeiro: Elsevier.

Shields, D., Solar, S., \& Martin, W. (2002). The role of values and objectives in communicating indicators of sustainability. Ecological Indicators, 2(1-2), 149-160. http://dx.doi.org/10.1016/S1470-160X(02)00042-0.

Siche, J. R., Agostinho, F., Ortega, E., \& Romeiro, A. (2007). Índices versus Indicadores: precisões conceituais na discussão da sustentabilidade de países. Ambiente \& Sociedade, 10(2), 137-148. http://dx.doi.org/10.1590/ S1414-753X2007000200009.

Singh, R. K., Murty, H. R., Gupta, S. K., \& Dikshit, A. K. (2007). Development of composite sustainability performance index for steel industry. Ecological Indicators, 7(3), 565-588. http://dx.doi.org/10.1016/j. ecolind.2006.06.004.

Singh, R. K., Murty, H. R., Gupta, S. K., \& Dikshit, A. K. (2009). An overview of sustainability assessment methodologies. Ecological Indicators, 15(1), 281-299. http://dx.doi.org/10.1016/j.ecolind.2011.01.007.

Staniškis, J. K., \& Arbačiauskas, V. (2009). Sustainability performance indicators for industrial enterprise management. Environmental Research, Engineering and Management, 48(2), 42-50.

Stubbs, W., \& Cocklin, C. (2008). Conceptualizing a 'Sustainability Business Model'. Organization \& Environment, 21(2), 103-127. http://dx.doi. org/10.1177/1086026608318042.

Valente, M. (2012). Theorizing firm adoption of sustaincentrism. Organization Studies, 33(4), 563-591. http://dx.doi. org/10.1177/0170840612443455.

Van Bellen, H. M. (2004). Indicadores de sustentabilidade - um levantamento dos principais sistemas de avaliação. Cadernos EBAPE.BR, 2(1), 1-14. http://dx.doi.org/10.1590/ S1679-39512004000100002.

Van Bellen, H. M. (2005). Indicadores de sustentabilidade: uma análise comparativa. Rio de Janeiro: FGV Editora.

Van Marrewijk, M., \& Werre, M. (2003). Multiple levels of corporate sustainability. Journal of Business Ethics, 44(23), 107-119. http://dx.doi.org/10.1023/A:1023383229086.

Vinodh, S. (2011). Assessment of sustainability using multi-grade fuzzy approach. Clean Technologies and Environmental Policy, 13(3), 509-515.

Vos, R. O. (2007). Defining sustainability: a conceptual orientation. Journal of Chemical Technology and Biotechnology, 82(4), 334-339. http://dx.doi.org/10.1002/ jctb.1675.

Warhurst, A. (2002). Sustainability indicators and sustainability performance management (No. 43, pp. 1-129). Warwick: IIED. Report to the project: Mining, Minerals and Sustainable Development (MMSD). Recuperado em 8 de agosto de 2012, de http://www.iied.org/mmsd/mmsd_pdfs/sustainability_ indicators.pdf

World Comission on Environment and Development WCED. (1987). Our common future: the Brundtland report. Oxford: Oxford University Press.

Yin, R. K. (2001). Estudo de caso: planejamento e métodos. São Paulo: Artmed.

Zamcopé, F. C., Ensslin, L., \& Ensslin, S. R. (2012). Construction of a model for corporate sustainability assessment: a case study in the textile industry. Gestão \& Produção, 19(2), 303-321. 
Apêndice 1. Símbolos e termos utilizados no trabalho (baseado em Krajnc \& Glavič, 2005).

\begin{tabular}{|c|c|}
\hline Símbolo & Significado \\
\hline$I_{A}^{+}$ & Indicador cujo valor crescente tem impacto positivo na sustentabilidade \\
\hline$I_{A}^{-}$ & Indicador cujo valor crescente tem impacto negativo na sustentabilidade \\
\hline$\hat{\mathrm{I}}_{A}^{+}$ & Valor médio do indicador com impacto positivo no período selecionado \\
\hline$\hat{\mathrm{I}}_{A}^{-}$ & Valor médio do indicador com impacto negativo no período selecionado \\
\hline$I_{C D S}$ & Índice Composto de Desenvolvimento Sustentável \\
\hline$I_{\min }^{+}$ & Indicador com valor mínimo e impacto positivo na sustentabilidade \\
\hline$I_{\min }^{-}$ & Indicador com valor mínimo e impacto negativo na sustentabilidade \\
\hline$I_{\max }^{+}$ & Indicador com valor máximo e impacto positivo na sustentabilidade \\
\hline$I_{\max }^{-}$ & Indicador com valor máximo e impacto negativo na sustentabilidade \\
\hline$I_{N}^{+}$ & Indicador normalizado cujo valor crescente tem impacto positivo na sustentabilidade \\
\hline$I_{N}^{-}$ & Indicador normalizado cujo valor crescente tem impacto negativo na sustentabilidade \\
\hline$I_{S}$ & Subíndice de sustentabilidade \\
\hline$\gamma_{E C N}$ & Taxa de desenvolvimento econômico da empresa no intervalo de tempo \\
\hline$\gamma_{S O C}$ & Taxa de desenvolvimento social da empresa no intervalo de tempo \\
\hline$\gamma_{A M B}$ & Taxa de desenvolvimento ambiental da empresa no intervalo de tempo \\
\hline$\gamma_{D S}$ & Taxa de desenvolvimento sustentável da empresa no intervalo de tempo \\
\hline $\mathrm{w}$ & Peso do indicador \\
\hline $\mathrm{i}$ & Índice de desenvolvimento sustentável \\
\hline $\mathrm{j}$ & Grupo de indicadores de desenvolvimento sustentável \\
\hline $\mathrm{t}$ & Tempo em anos \\
\hline
\end{tabular}

